\title{
LETTER
}

\section{Which is the most effective strategy: early detection of coagulopathy with thromboelastometry or use of hemostatic factors or both?}

\author{
Jean-Stephane David*1 ${ }^{* 1}$ Virginie Marchal', Albrice Levrat ${ }^{1}$ and Kenji Inaba² \\ See related research by Schöchl et al., http://ccforum.com/content/15/2/R83
}

In an article in the previous issue of Critical Care, Schöchl and colleagues suggested that, in trauma patients, a hemostatic strategy combining the use of fibrinogen concentrates or prothrombin complex concentrates (PCCs) (or both) guided by thromboelastometry resulted in a reduction of exposure to allogeneic blood products when compared with a strategy using fresh frozen plasma (FFP) guided by standard coagulation assays [1]. The primary concern with this analysis is the comparison of a series of patients treated at a single center with a highly protocolized approach to transfusion against a registry-based cohort of patients from multiple centers with no standardized protocol. Also, several very specific biases introduced into the analysis are of concern. First, the time required to obtain a hemostatic result varied greatly between groups, ranging from less than 15 minutes with the rotation thrombelastography
(ROTEM) to usually more than 45 to 60 minutes in the standard group [2]. The timing of coagulation component replacement must be factored into this analysis. The second bias centers around the concentration of fibrinogen delivered: $3 \mathrm{~g}$ of fibrinogen (median of 6 units of FFP) in the FFP group versus a median of $6 \mathrm{~g}$ in the fibrinogenPCC group. Previous reports have demonstrated a close relationship between blood loss and fibrinogen level $[3,4]$.

Finally, it should be noted that thromboelastometry is not mandatory for the use of PCC and fibrinogen [5]. Although the use of thromboelastometry and a hemostatic strategy combining fibrinogen and PCC is very attractive, further controlled studies will have to determine which part of this strategy is really effective: early detection of coagulopathy or a combination of hemostatic factors or both?

\section{Authors' reply}

Herbert Schöchl and Cristina Solomon

We thank David and colleagues for their comments. We acknowledged in our paper that there are limitations to the comparison of patients treated in one center according to a protocol with those from multiple centers with no standardized protocol. Thus, our results are not as robust as those from randomized controlled trials but do represent the only published controlled study of combined fibrinogen concentrate and PCC in trauma.

*Correspondence: jean-stephane.david@chu-lyon.fr

'Hospices Civils de Lyon, Lyon-Sud Hospital and University Lyon 1, Department of Anesthesiology and Critical Care,165 Chemin du Grand Revoyet, F-69495 Pierre Benite, France

Full list of author information is available at the end of the article
David and colleagues described two biases, which relate to differences in time taken to obtain hemostatic results and fibrinogen dose. However, these are not biases. Instead, they represent inherent differences between the two treatment approaches and their inclusion ensures that the study is applicable to clinical practice. The point regarding fibrinogen dose is interesting as the dose of FFP required to increase the fibrinogen level by a certain amount is dependent on the starting point. Much higher volumes are needed to increase the fibrinogen level from 1 to $1.5 \mathrm{~g} / \mathrm{L}$ compared with 0.5 to $1.0 \mathrm{~g} / \mathrm{L}$. The dose-response curve for fibrinogen administered via FFP is not linear, and the required dose increases exponentially as the target level approaches $2 \mathrm{~g} / \mathrm{L}$, which is the mean concentration in FFP [6]. 
David and colleagues comment that use of thromboelastometry is not mandatory. Although this is true, the risk-benefit profile of coagulation factor concentrates can almost certainly be improved by thromboelastometry. In thromboelastometry (in contrast to fixed-dose therapy), assessment of the patient's coagulation status before treatment and monitoring of the post-treatment response (feedback loop) allow under- or over-treatment to be avoided.

The improvements reported in our study are attributable to changes in both therapy and diagnostics. We agree that it would be interesting to prospectively assess the relative contributions of these two aspects.

\section{Abbreviations}

FFP, fresh frozen plasma; PCC, prothrombin complex concentrate.

\section{Competing interests}

This study was performed without external funding. HS, CS, and MM have received honoraria as speakers and research support from CSL Behring (King of Prussia, PA, USA) (manufacturer of fibrinogen concentrate and PCC) and Tem International GmbH (Munich, Germany) (manufacturer of the TEM device). AH has received honoraria as speaker and research support from CSL Behring. GH is an employee of CSL Behring. All other authors declare that they have no competing interests. Editorial assistance was provided by Ken Sutor, of Fishawack Communications Ltd (Knutsford, UK), during late-stage development of this manuscript. Financial support for this assistance was provided by CSL Behring $\mathrm{GmbH}$.

\section{Author details}

'Hospices Civils de Lyon, Lyon-Sud Hospital and University Lyon 1, Department of Anesthesiology and Critical Care,165 Chemin du Grand Revoyet, F-69495 Pierre Benite, France. ${ }^{2}$ Division of Trauma Surgery and Surgical Critical Care,
University of Southern California, USC LAC Medical Center, 1200 North State Street, Inpatient Tower (C)-Room C5L100, Los Angeles, CA 90033, USA.

Published: 13 June 2011

\section{References}

1. Schöchl H, Nienaber U, Maegele M, Hochleitner G, Primavesi F, Steitz B, Arndt C, Hanke A, Voelckel W, Solomon C: Transfusion in trauma: thromboelastometry-guided coagulation factor concentrate-based therapy versus standard fresh frozen plasma-based therapy. Crit Care 2011 15:R83.

2. Rossaint R, Bouillon B, Cerny V, Coats TJ, Duranteau J, Fernandez-Mondejar E, Hunt BJ, Komadina R, Nardi G, Neugebauer E, Ozier Y, Riddez L, Schultz A, Stahel PF, Vincent JL, Spahn DR: Management of bleeding following major trauma: an updated European guideline. Crit Care 2010, 14:R52.

3. Fenger-Eriksen $C$, Lindberg-Larsen $M$, Christensen $A Q$, Ingerslev J, Sørensen B: Fibrinogen concentrate substitution therapy in patients with massive haemorrhage and low plasma fibrinogen concentrations. Brit J Anaesth 2008, 101:769-773

4. Stinger HK, Spinella PC, Perkins JG, Grathwohl KW, Salinas J, Martini WZ, Hess JR, Dubick MA, Simon CD, Beekley AC, Wolf SE, Wade CE, Holcomb JB: The ratio of fibrinogen to red cells transfused affects survival in casualties receiving massive transfusions at an army combat support hospital. J Trauma 2008, 64(2 Suppl):S79-S85.

5. Bruce D, Nokes TJC: Prothrombin complex concentrate (Beriplex $\mathrm{P} / \mathrm{N}$ ) in severe bleeding: experience in a large tertiary hospital. Crit Care 2008, 12:R105.

6. Theusinger OM, Baulig W, Seifert B, Emmert MY, Spahn DR, Asmis LM: Relative concentrations of haemostatic factors and cytokines in solvent/ detergent-treated and fresh-frozen plasma. Br J Anaesth 2011, 106:505-511.

doi:10.1186/cc10224

Cite this article as: David J-S, et al.: Which is the most effective strategy: early detection of coagulopathy with thromboelastometry or use of hemostatic factors or both? Critical Care 2011, 15:433. 